\title{
Time-Cost Relationship in Road and Highway Construction
}

\section{Dr. Ifte Choudhury, Texas A\&M University}

Ifte Choudhury is an Associate Professor in the Department of Construction Science at Texas A\&M University and has extensive experience as a consulting architect working on projects funded by the World Bank. His areas of emphasis include housing, alternative technology, issues related to international construction, and construction education. He is also a Fulbright scholar. 


\title{
Time-Cost Relationship in Roads and Highways Construction
}

\begin{abstract}
Time-Cost relationship has been found to be valid for different construction types by many researchers. The purpose of this study is to validate this relationship, based on a model developed by Bromilow et al., for highway construction in Florida. Along with time and cost factors, the modified model included contract types to determine whether this variable also has an effect on project duration. Data related to 235 roads and highways construction projects was obtained for the study. SPSS ${ }^{\circ}$ program was used for analysis of the data. The statistical technique used for the analysis was multiple regression. The results indicate that both actual construction cost and contract type have got a statistically significant relationship with construction time for highway construction projects, at the level of significance (p-value) of $<0.0001$. A prediction model of construction time has been developed based on the results of the study. This model will be useful to both graduate and undergraduate students taking courses related to cost estimating and construction project scheduling, and also to professionals involved with the construction industry. A study such as this one will also be helpful to the students in Construction Management to understand the goals of statistical modeling.
\end{abstract}

Keywords: Construction Time, Construction Cost, Contract Type, Road Construction, Regression Analysis

\section{Introduction}

\section{General}

Construction time for any type of project is related to a wide range of variables including construction cost. Time and cost have been typically used as important criteria for determining project performance globally. A relationship exists between the time taken for construction of a project and the cost incurred to complete it. Project cost has been identified as a correlate of construction time in many regions of the world ${ }^{1,2}$. In the construction industry, contractors usually use previous experiences to estimate the project duration and cost of a new project. In general, the more time it takes to complete an activity, the more human resources have to be engaged for the task, resulting in a higher project cost.

A correlation between completed construction cost and the time taken to complete a construction project was first mathematically ascertained by Bromilow et al. ${ }^{1}$ The authors analyzed the time-cost data for a total of 419 building projects in Australia to develop the model. The equation defining the mean construction time as a function of project cost was found to be:

$\mathrm{T}=\mathrm{K}^{*} \mathrm{C}^{\mathrm{B}}$

Where

$\mathrm{T}=$ duration of construction period from the date of possession of site to substantial completion, in working days

$\mathrm{C}=$ completed cost of project in millions of dollars, adjusted to constant labor and material prices 
$\mathrm{K}=\mathrm{a}$ constant indicating the general level of time performance per million dollar

$\mathrm{B}=\mathrm{a}$ constant describing how the time performance is affected by the size of the construction project measured by its cost.

The model indicates that the duration of project time of a construction project is basically a function of its total cost. It provided a basis for all parties concerned with the construction procedure to establish a fairly accurate probable duration of a project in days, given the estimated cost of the project. The authors also analyzed the overruns on cost and time that provided a measure on the accuracy of the industry's time and cost prediction.

The model also indicates that relationship between duration of a construction project and time required to complete it is non-linear (Figure 1). In order to perform data analysis using a linear model, the variables need to be transformed into their natural logarithms.

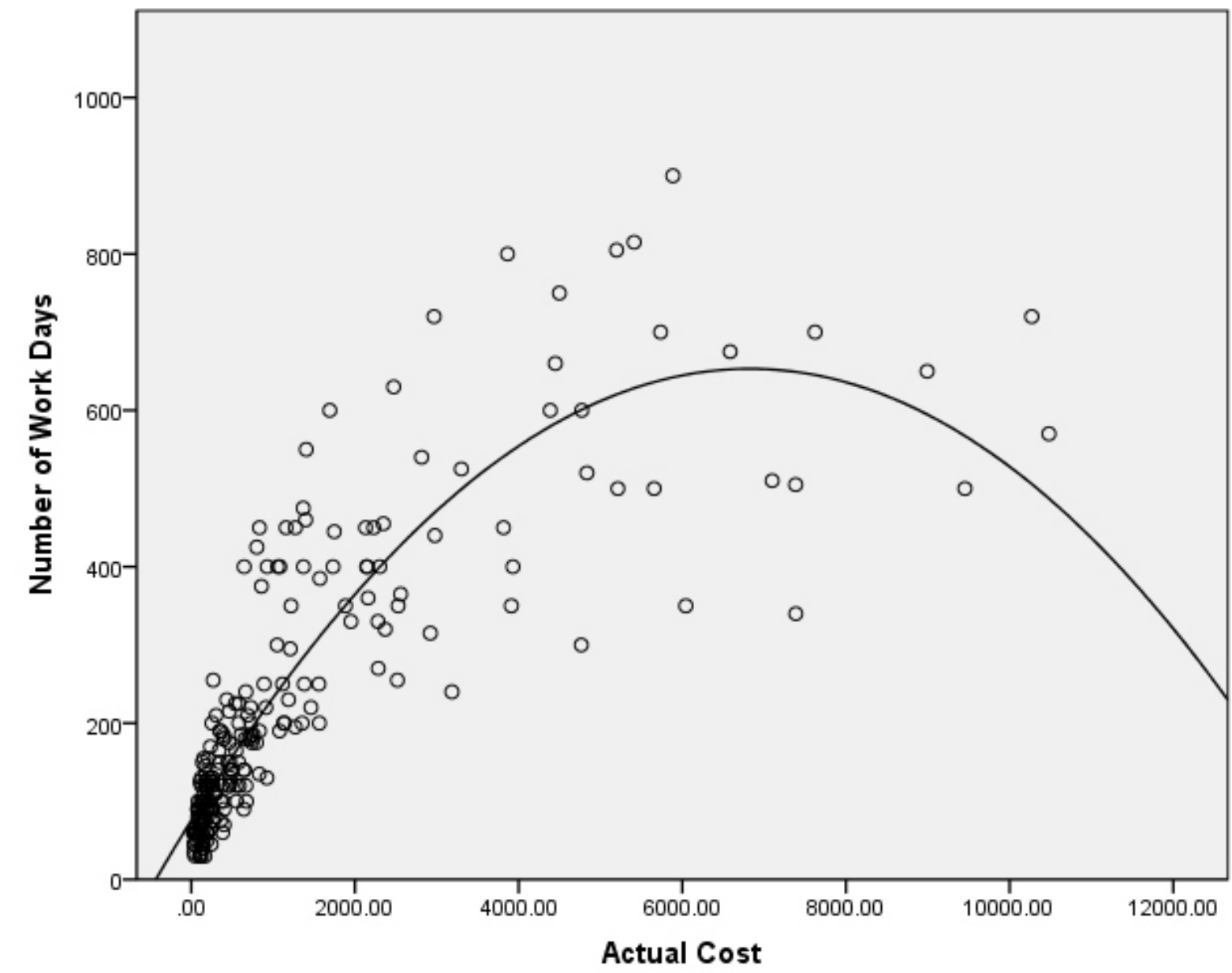

Figure 1. Non-linear relationship between construction cost and time

Several other studies have been performed around the world to make similar predictions for either a specific sector of construction or construction industries, in general. Ireland ${ }^{3}$ replicated the study to predict construction time for high-rise buildings in Australia; Kaka \& Price 4 conducted a similar survey both for buildings and road works in the United Kingdom; Chan ${ }^{5}$ investigated the effect of construction cost on time with particular reference to Hong Kong; and Choudhury \& Rajan ${ }^{2}$ conducted a study on residential construction projects in Texas. Hoffman et al. ${ }^{6}$ used Bromilow et al.'s ${ }^{1}$ time-cost model to analyze data collected for 856 
facility projects. They, however, included certain other variables such as project location, building type, and delivery method in the model.

Gritzka \& $\mathrm{Labi}^{7}$ conducted a study on factors of time delay, specifically for road construction projects. Findings of their study indicate a statistically significant relationship between longerduration projects and cost overrun.

All these studies found that the mathematical model developed by Bromilow et al. ${ }^{1}$ holds good for prediction of construction time when the cost of construction is known.

\section{Other Possible Factors of Road Construction}

A critical issue in road construction that affect project delivery, experienced almost worldwide, is cost overrun ${ }^{8}$. It generally results from factors that occur during various stages of life-cycle of a project. Studies on highway projects have been conducted by quite a few researchers to seek the extent of this particular problem.

Findings by several authors indicate that it is associated with project design, project environment, and project size $\mathrm{s}^{9,10}$; project size, of course, is directly related to overall construction time.

Construction procurement is the process of obtaining services and supplies for efficient and timely delivery of the end product. The major project delivery methods include (1) DesignBid-Build, (2) Design-Build, and (3) Construction Management at Risk. Studies indicate that project performance is affected by project delivery method ${ }^{11,12,13}$.

The trend in the use of project delivery system is changing rapidly. Project delivery system has evolved over the years. The medieval master builder was hired by an owner to design, engineer, and construct an entire facility. This system was common until the early 20th century. With changing technologies, it was necessary to change the type of delivery system that gave way to the Design-Bid-Build method. As the specialization of services increased, it was found that the interaction during design phase was extremely poor which resulted in inefficient designs, increased errors and disputes, higher costs, and ultimately longer schedule. This led to the Construction Management at Risk delivery system to improve the interaction among parties concerned and to overlap the design and the construction phases. Eventually, it was found necessary for owners to resort to a single source Design-Build contracting ${ }^{14}$. There is an increasing trend toward the use of the Design-Build delivery method in the public sector ${ }^{11,15,16}$.

It is thus possible that project delivery method could play a role in construction performance time. The likelihood of an impact of delivery method on construction time of road projects was ascertained by including it in the time-cost relationship model.

\section{Hypotheses}

From a review of literature, it is hypothesized that

1. The actual completion time of road construction projects in Florida is affected by actual construction cost.

2. The actual completion time of road construction projects in Florida is affected by estimated construction cost.

3. The actual completion time of road construction projects in India is affected by contract type or delivery method. 


\section{Methodology}

\section{Data Collection}

Data for 235 completed road construction projects undertaken by Florida Department of Transportation (FDOT) was obtained from secondary sources. All construction works were completed within last five years.

\section{Variables}

Actual Construction Time (TIME): It is the actual time measured for the completion of a road construction project. It was measured in days. This variable was labeled as LNTIME after being transformed into its natural logarithm.

Actual Project Cost (ACOST): It is the total cost of construction works of a road construction project. It was measured in units of 1000 US Dollars. This variable was labeled as LNACOST after being transformed into its natural logarithm.

Estimated Project Cost (ECOST): It is the total cost of construction works of a road construction project, estimated by FDOT prior to construction. It was measured in units of 1000 US Dollars. This variable was labeled as LNECOST after being transformed into its natural logarithm.

Contract Type (CONT): It is the type of contracting used for delivering a road construction project. This was a dummy variable consisting of two categories: (1) Design-Build (DB), and (2) Others. This variable was labeled as LNCONT after being transformed into its natural logarithm. It was assigned a value of 1 , if the contracting method was DB; if not, a value of 0 was assigned.

\section{Results}

\section{Analysis}

The time-cost relationship model developed by Bromilow et al. ${ }^{1}$ (1980) defines only the relationship between construction time and actual construction cost. Since the present study hypothesizes relationships to exist also between (1) construction time and estimated construction cost and (2) construction time and contract type, the model had to be modified. Following model encompasses both the variables that may have an effect on construction time performance:

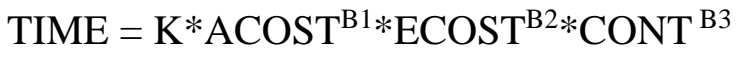

A stepwise linear regression analysis was used to perform the first step of analysis (see eqn. 3). It is a semi-automated process of building a model by successively adding or removing variables based on the $t$-statistics of their estimated coefficients. Therefore, the variables had to be transformed into their natural logarithms.

$$
\mathrm{LNTIME}=\mathrm{LNK}+\beta_{1} \mathrm{LNACOST}+\beta_{2} \mathrm{LNECOST}+\beta_{3} \mathrm{LNCONT}+\varepsilon
$$

Where $\mathrm{LNK}=$ natural logarithm of $\mathrm{K} ; \beta_{1}, \beta_{2}, \beta_{3}=$ regression coefficients; and $\varepsilon=$ error term.

The results show that two independent variables were retained by the model: actual construction cost (LNACOST) and contract type (LNCONT). Estimated contract cost 
(LNECOST), not being significant at the level of 0.5 , was were excluded. The results are shown in Table 1.

Table 1: Stepwise Linear Regression Analysis for LNTIME

\begin{tabular}{|l|l|l|l|l|l|}
\hline Variable Retained & $\begin{array}{l}\text { Intercept } \\
(\text { LNK })\end{array}$ & $\begin{array}{l}\text { Regression } \\
\text { Coefficient }\end{array}$ & $t$ & $p<|t|$ & $\begin{array}{l}\text { Critical } \\
\text { Value of }|t|\end{array}$ \\
\cline { 1 - 4 } Intercept & 1.827 & & 15.976 & $<0.0001$ & 1.96 \\
\cline { 1 - 2 } & & 0.529 & 29.976 & $<0.0001$ & \\
\cline { 1 - 2 } $\begin{array}{l}F \text {-value of the Model }= \\
459.471\end{array}$ & $\begin{array}{l}p>\text { Model } \\
F=<0.0001\end{array}$ & $\begin{array}{l}\text { Model } R^{2}=0.89 \\
\text { Adjusted model } R^{2}=0.80\end{array}$ \\
\hline
\end{tabular}

\section{Interpretations}

The $F$-value of the model used for multiple regression analysis was found to be statistically significant at less than the 0.0001 level. This provides evidence that a relationship exists between construction time and at least one of the independent variables used in the model. The results, however, indicate that the actual construction cost and contract type are is correlated to construction time at a very high level of significance with a $p$-value 0.0001 and 0.026 respectively. Estimated construction cost was not found to be significant at level of significance of 0.05 ; hence, it was automatically excluded by the statistical program from the model.

An important aspect of a statistical procedure that derives model from empirical data is to indicate how well the model predicts results. A widely used measure the predictive efficacy of a model is its coefficient of determination, or $R^{2}$ value. If there is a perfect relation between the dependent and independent variables, $R^{2}$ is 1 . In case of no relationship between the dependent and independent variables, $R^{2}$ is 0 . Predictive efficacy of this particular model was found to be moderately high with an $R^{2}$ of 0.89 , and an adjusted $\mathrm{R}^{2}$ of 0.80 . It means that at least 80 percent of the variances in construction time of projects are explained by actual construction cost and contract type.

Based on the findings, research hypotheses indicating relationships between (1) actual completion time and cost of road construction projects (Figure 2) and (2) actual completion time and contract types for road construction projects in Florida could not to be rejected. However, the other hypothesis indicating a relationship between actual completion time and estimated construction cost for road projects in Florida had to be rejected.

The relationship between time and cost was found to statistically significant at the level of less than 0.0001. The relationship between time and contract type was found to be inverse at the level of less than 0.026 . It means that construction duration was less using design-build type of contract. 


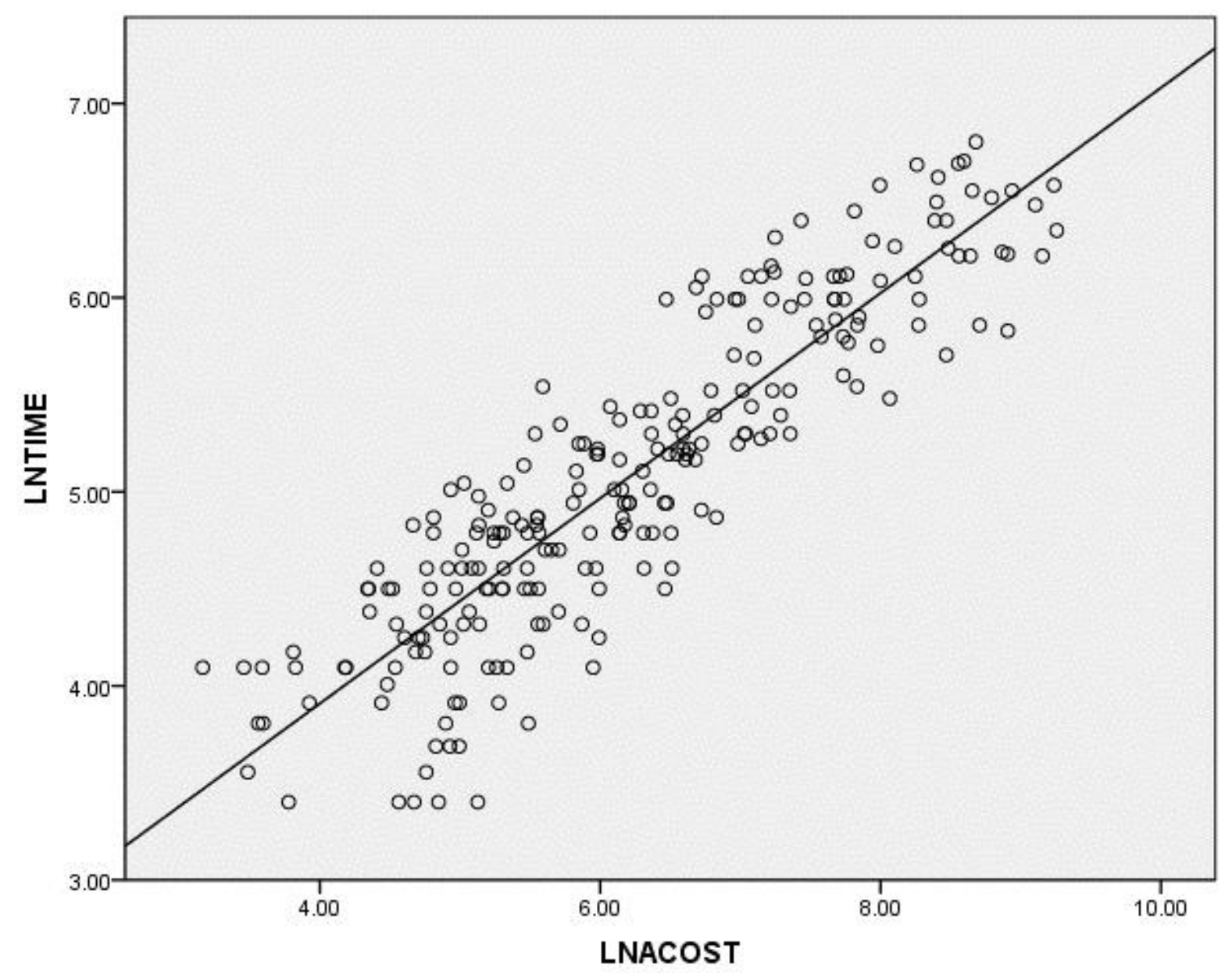

Figure 2. Relationship between LNTIME and LNCOST

The prediction model for road construction time in Florida was developed using results of the analysis. Bromilow et al.'s ${ }^{1}$ (1980) model was modified by adding contract type to the equation. The value of LNK and LNCONT were required to be transformed to K, using an exponential function $[\exp (\mathrm{LNK})]$ and $[\exp (\mathrm{LNCONT})]$ respectively, for expressing the model in its original form (Equation 4). The model may be expressed as follows:

$\mathrm{TIME}=6.215^{*} \mathrm{ACOST}^{0.529} * \mathrm{CONT}^{-1.31}$

\section{Relevance of the Study to Construction Education}

Statistical models enable empirically-observed measurements, that is, data from the real world, to be interpreted in terms of theory. In many courses in Construction Management, particularly at the graduate level, there is a marked emphasis on collection and interpretation of data. The courses include Advanced Project Management, Construction Economics, Construction Information Systems, and many others. Model management has evolved as an area of emphasis in Construction Information Systems. It involves the methods of storing, modifying, and manipulating models. The domain is composed of dynamic, temporal relationships between variables. With a comprehensive understanding of the data, the students can truly position their works to be viable. Finally, after graduation, they may be responsible for leading large projects with significant costs, technical complexity, and responsibility. Statistical methods allow construction managers to make a consistent product, detect problems, minimize waste, and predict project success. A study such as this one will be helpful to the students in Construction 
Management to understand the goals of statistical modeling, including accurate predictions, the interpretation of effects, and identification of key factors for further modeling and analysis.

\section{Conclusions}

The results of the statistical analysis indicate that for a road construction project in Florida, an increase in construction results in an increase in total construction time. The results also indicate that contract type has a statistically significant effect on actual construction time of the projects. It takes less time for completion of a road project in Florida using design-build method of delivery.

The model will be useful for students of construction management, taking courses in Advanced Project Management, Construction Economics, and Construction Information. It will also be useful for all parties associated with the construction industry to predict the mean time required for the delivery of a road project. It provides an alternative and logical method for estimating construction time, both by bidders and clients, to supplement the prevailing practice of estimation predominantly on individual experience.

This study has been conducted using data for construction of road projects in Florida. The construction industry can benefit from the results of the study by applying the model in predicting construction time for similar projects. Such models may be developed by collecting historical data either from the owners or the constructors. However, the model documented in this study applies only for road construction projects in Florida and cannot be generalized beyond the sample size.

Bibliography

1. Bromilow F J, Hinds M F and Moody N F (1980) "AIQS survey of building contract time performance." Building Economist 19(2): 79-82.

2. Choudhury I and Rajan S S (2008) "Time-cost relationship for residential construction in Texas." The American Professional Constructor 32(2): 28-32.

3. Ireland V B E (1985) "The role of managerial actions in the cost, time, and quality performance of high-rise commercial building projects." Construction Management and Economics 3 (1): 59-87.

4. Kaka A and Price A D F (1991) "Relationship between value and duration of construction projects." Construction Management and Economics 9(4): 383-400.

5. Chan A P C (1999) "Modeling building durations in Hong Kong." Construction Management and Economics 17(2): 189-196.

6. Hoffman G J et al. (2007) "Estimating performance time for construction projects." Journal of Management Engineering. 23(4): 193-199.

7. Gritzka, K and Labi, S (2008). "Estimating cost discrepancies in highway contract: A multistep econometric approach." Journal of Construction Engineering and Management, 134(12): 953-962.

8. Bhargava, A et al. (2010) "Three-Stage Least-Squares Analysis of Time and Cost Overruns in Construction Contracts." Journal of Construction Engineering and Management 136(11): 1207-1218.

9. Akinci, B and Fisher, M (1998). "Factors affecting contractor's risk of cost overburden." Journal of Management Engineering 14(1): 67-76.

10. Hinze, J, Selstead, G, and Mahoney, J P (1992) "Cost overrun on state of Washington construction contracts." Transportation Research Record 1351: 87-93.

11. Choudhury, I and Pitkar, M (2007). "An analysis of project delivery systems in commercial construction," Journal of American Institute of Constructors, 31(1): 23-27.

12. Ling, F Y Y et al. (2004). "Predicting performance of design-build and design-bid-build projects," Journal of Construction Engineering and Management, 130(1): 75-83.

13. Chan, A P C, Scott, D. and Lam, E. W. M. (2002). "Framework of design criteria for design-build projects," Journal of Management in Engineering, 18(3): 12-128. 
14. El-Wardani, M A, Messner, J I, and Horman, M J (2006). "Comparing procurement methods for design-build projects," Journal of Construction Engineering and Management, 132(3): 230-238.

15. Tulacz, G (2006). "Design-build continues to grow despite weariness and price concerns," ENR, 256(23): 38.

16. Yakowenko, G (2004). "Megaproject procurement: Breaking from tradition," Public Roads, 68(1): 48-53. 